\title{
Relato de experiência de um Serviço de Emergência do interior do Rio de Janeiro com a Pandemia de COVID-19
}

\section{Report of Experience from an Emergency Department in the interior of Rio de Janeiro With the Pandemic of COVID-19}

\section{Relato de la experiencia de un servicio de emergencias del interior de Río de Janeiro con la pandemia de COVID-19}

Gefson Couto Magrani ${ }^{*}$, Lívia Liberata Barbosa Bandeira ${ }^{2}$, Sara Cristine Marques dos Santos ${ }^{3}$, Carolina de Paula Orioli da Silva ${ }^{4}$, Eduardo Tavares Lima Trajano ${ }^{5}$, Ivana Picone Borges de Aragão ${ }^{6}$

Como citar esse artigo. Magrani, GC; Bandeira, LLB; Santos, SCM; Silva, CPO; Trajano, ETL; Aragão, IPB. Relato de experiência de um serviço de emergência do interior do Rio de Janeiro com a pandemia de COVID-19. Revista Pró-UniverSUS. 2021 Jan./Jun.; 12 (1): $14-18$

\section{Resumo}

A pandemia causada pelo COVID-19 é atualmente um problema de saúde pública internacional. Trata-se de um vírus altamente transmissível, através de pessoas sintomáticas, por contato com aerossóis e uso de objetos compartilhados. A sintomatologia mais prevalente tem a apresentação de febre, dor de garganta e tosse. O presente estudo teve como objetivo relatar a experiência na "linha de frente", como diretor médico da UPA no interior do Rio de Janeiro, no enfrentamento da pandemia, onde foi preciso realizar a orientação em relação as medidas preventivas aos trabalhadores do sistema de saúde e a população em geral. Houve a implantação de fluxogramas de atendimento e detecção precoce para acolhimento do paciente com suspeita de COVID. Tal medida, possibilitou maior controle sobre as ações realizadas, com taxa de mortalidade menor que a média nacional e recuperação em $85 \%$ dos casos.

Palavras-chave: Infecções por Coronavirus; Betacoronavirus; Vírus da SARS.

\section{Resumen}

La pandemia causada por COVID-19 es actualmente un problema de salud pública internacional. Es un virus altamente transmisible, a través de personas sintomáticas, por contacto con aerosoles y uso de objetos compartidos. La sintomatología más prevalente tiene la presentación de fiebre, dolor de garganta y tos. Este estudio tuvo como objetivo relatar la experiencia en la "línea de frente", como director médico de la UPA en el interior de Río de Janeiro, en el enfrentamiento de la pandemia, donde fue necesario realizar la orientación sobre las medidas preventivas a los trabajadores del sistema de salud y a la población en general. Se implementaron flujogramas de atención y detección temprana para recibir al paciente con sospecha de COVID. Esta medida permitía un mayor control sobre las acciones realizadas, con una tasa de mortalidad menor que la media nacional y la recuperación en el $85 \%$ de los casos.

Palabras clave: Infecciones por coronavirus; Betacoronavirus; Virus del SARS.

Afiliação dos autores:

${ }_{1}^{1}$ Mestre pelo Mestrado Profissional em Ciências Aplicadas em Saúde da Universidade de Vassouras, Vassouras, Rio de Janeiro, Brasil. ORCID: https://orcid.org/0000-0003-19469688 .

${ }^{2}$ Graduada pelo Curso de Medicina da Universidade de Vassouras, Vassouras, Rio de Janeiro, Brasil. ORCID: https://orcid.org/0000-0002-7305-3504.

${ }^{3}$ Discente do Curso de Medicina da Universidade de Vassouras, Vassouras, Rio de Janeiro, Brasil. ORCID: https://orcid.org/0000-0002-8205-8112.

${ }^{4}$ Graduada pelo Curso de Medicina da Universidade de Vassouras, Vassouras, Rio de Janeiro, Brasil. ORCID: https://orcid.org/0000-0002-4520-0925.

5 Doutor. Docente e Coordenador do Mestrado Profissional em Ciências Aplicadas em Saúdeda Universidade de Vassouras, Vassouras, Rio de Janeiro, Brasil. ORCID: https://orcid. org/0000-0001-7809-7138

${ }^{6}$ Doutora. Docente do Curso de Medicina e do Mestrado de Ciências Médicas da Universidade de Vassouras, Vassouras, Rio de Janeiro, Brasil. ORCID: https://orcid.org/0000-00024295-0165.

* Email de correspondencia: gefsonmagrani@hotmail.com

Recebido em: 27/11/20. Aceito em: 30/11/20. 


\section{Introdução}

A pandemia de COVID-19 - Coronavirus Disease-2019, doença infecciosa causada pelo SARS-CoV-2 - Severe Acute Respitaroty Syndrome Coronavirus 2, inicialmente reportado na cidade de Wuhan, na China, é hoje um problema de saúde pública e emergência internaciona ${ }^{11}$. É um vírus altamente transmissível, sendo a forma de contágio através pessoas infectadas, sintomáticas ou não, por meio do uso de objetos compartilhados, aerossóis, espaços fechados e que pode culminar em pneumonia e síndrome da angústia respiratória aguda grave em pacientes que cursam com a forma grave da doença ${ }^{2-4}$.

Em dezembro de 2019, na China casos de pneumonia de etiologia desconhecida foram registrados e notificados a Organização Mundial da Saúde (OMS). Em janeiro de 2020 houve a identificação do novo coronavírus e um melhor detalhamento pelo governo Chinês foi informado a OMS, associando-se a exposição causada por um mercado de frutos do mar na localidade de Wuhan.

Ao final de janeiro foi declarado pela OMS uma declarou Emergência de Saúde Pública de Importância Internacional (ESPII). No Brasil, através da Portaria MS n ${ }^{\circ} 188$, foi declarada Emergência de Saúde Pública de Importância Nacional (ESPIN) pelo vírus SARSCoV-2. A mesma portaria também apresentou oCentro de Operações de Emergências em Saúde Pública $(\mathrm{COEnCoV})$ para gerir coordenadamente de forma nacional a resposta de combate ao novo vírus, sob responsabilidade da Secretaria de Vigilância em Saúde. Em março, foi declarada a pandemia pela OMS.

Os sintomas mais comuns são febre, dor de garganta, dispnéia, tosse seca, cansaço e alguns reportaram diarréia, náuseas e coriza nasal ${ }^{5,6}$. Estudos mostram que idade acima de 60 anos e a presença de doenças preexistentes, como o diabetes mellitus, hipertensão, obesidade são considerados fatores de risco para o desenvolvimento da forma mais grave da doença e com maior mortalidade ${ }^{7-9}$. Em crianças, a ação do vírus clinicamente tem melhor prognóstico e de forma discreta, sendo raros os casos de morte ${ }^{10}$.

\section{Metodologia}

Trata-se de um relato de experiência por um médico diretor da Unidade de Pronto Atendimento (UPA) no interior do Rio de Janeirosobre o enfrentamento a pandemia de COVID-19.

\section{Resultados}

Experiência pessoal com a política e ações do governo

Na segunda semana de março, o Brasil registrou seu primeiro óbito pela COVID-19. A partir do dia 13 no mesmo mês, houve uma reunião no gabinete do prefeito para formar uma comissão responsável pelo enfrentamento no município de Três Rios que pratico a medicina como clínico e diretor médico da Unidade de pronto atendimento - UPA onde todas as medidas necessárias para impedir o avanço da pandemia, como também,estratégias de atendimento foram formuladas e implementadas por meio de protocolos.

As ações da Secretaria Municipal de Saúde e Defesa Civil serão norteadas pelas portarias/resoluções emanadas pelo Ministério da Saúde e Secretaria de Saúde do Estado do rio de Janeiro (SES-RJ).

Até o presente momento várias ações estão sendo desenvolvidas pelo município de Três Rios para o enfrentamento da pandemia do coronavírus. Além das orientações e normas relacionadas às medidas de proteção coletiva, faz-se necessário orientar aos servidores do subsistema de urgência sobre as medidas de prevenção individuais e aos usuários do Sistema Único de Saúde.

Segue abaixo, os seguintes Decretos:

- Decreto Municipal No 6257 de 13 de março de 2020, que dispõe sobre as medidas que poderão ser adotadas, no âmbito da Administração Pública do Município de Três Rios, para enfrentamento da emergência de saúde pública de importância internacional decorrente do novo Coronavírus (2019$\mathrm{nCoV}$ );

- Decreto $N^{\circ} .6264$ de 13 de março de 2020, que suspende todos os pedidos de férias e revoga todas as autorizações para seu gozo, por razões de ordem pública, de todos os servidores da secretaria municipal de saúde e defesa civil - SMSDC, bem como todo e qualquer afastamento a pedido do serviço público e dá outras providências;

- Decreto No. 6265 DE 13 de março de 2020 que dispõe sobre a criação do gabinete de crise para enfrentamento da emergência de saúde pública de importância internacional decorrente do novo coronavírus, e da outras providências.

- Decreto Municipal No 6258 de 15 de março de 2020, que dispõe sobre as medidas para enfrentamento da emergencia de saude publica de importância internacional decorrente do novo coronavirus (2019nCOV), e dá outras providencias.

\section{Experiência com o Enfrentamento}

Como diretor médico da Unidade de Pronto Atendimento - UPA no interior do Rio de Janeiro, assumi a responsabilidade junto aos gestores do município para pôr em prática as estratégias e protocolos postos em vigor. Houve capacitações internas com todos os funcionários 
no que se refere à biossegurança e conhecimento do novo protocolo de atendimento implantado. Foram feitas diversas campanhas de informação para orientar a população, quando e onde procurar atendimento caso apresente sintomas correlacionados à COVID-19. O município criou uma Central de Atendimento ao Usuário do SUS, com número amplamente divulgado nas redes sociais da Prefeitura, (24) 2255-2820, com atendentes treinados para informar quando, como e onde procurar atendimento em caso de necessidade.

Visando a proteçãoe minimização da disseminação do vírus, a primeira medida foi montar um Centro de Triagem ao Paciente com Suspeita de COVID-19, próximo à UPA, cerca de $100 \mathrm{~m}$, que teve início dos trabalhos realizados no dia 24/03/2020, contanto com um médico, um enfermeiro e um técnico de enfermagem 24h/dia, além de uma ambulância exclusiva, objetivando desviaro fluxo desses pacientes de dentro da UPA, uma vez que os atendimentos clínicos às outras enfermidades continuaram sem interrupção.

Os pacientes que clinicamente estão portadores de sintomas gripais são notificados junto ao Serviço de Epidemiologia do Município, é feito o teste rápido e colhido swab nasal.Nos casos de sintomas gripais leves, os pacientes são orientandos a manter o isolamento domiciliar e passam a ser monitorados pelo Serviço de Atenção Domiciliar com ligações diárias. Em caso de piora ou agravamento do quadro os pacientes são encaminhados a UPA $24 \mathrm{H}$ para realização de exames laboratoriais como hemograma, gasometria arterial, radiografia do tórax e tomografia computadorizada do tórax, sendo essa última realizada em serviço terceirizado - PROSCAN, situada dentro do Hospital Congregação Nossa Senhora da Conceição - HCNSC. Com os exames em mãos e dependendo da gravidade do quadro o paciente é regulado (Via Central de Regulação Municipal) para o HCNSC, que dispõe de 8 leitos UTICOVID ou para o Centro de Internação Intermediária, alocado dentro do PSF Boa União, contendo 13 leitos. O transporte dos pacientes é feito com ambulância própria de uso exclusivo ao enfrentamento ao COVID.

\section{Sucesso com a estratégia ou experiência com o fluxograma}

Com a implementação do plano de enfretamento ao COVID-19 no Município de Três Rios já no início da Pandemia, observou-se um controle maior sobre as ações promovidas e consequentemente uma taxa de sucesso maior em relação ao número de pacientes recuperados.

Até a data de 27 de agosto de 2020, o Município notificou 5.592, entre estes, 2.790 casos confirmados, 65 óbitos.Avaliando-se os números é possível notar uma taxa de recuperação em torno de $85 \%$ dos casos, compatível com a média nacional que também é de $80 \%$
FLUXOGRAMA PARA ATENDIMENTO E DETECÇÃO PRECOCE DE COVID-19 EM HOSPITAL DE REFERÊNCIA PARA INDIVÍDUOS POR DEMANDA ESPONTÂNEA PREFEITURA DE TRÊS RIOS

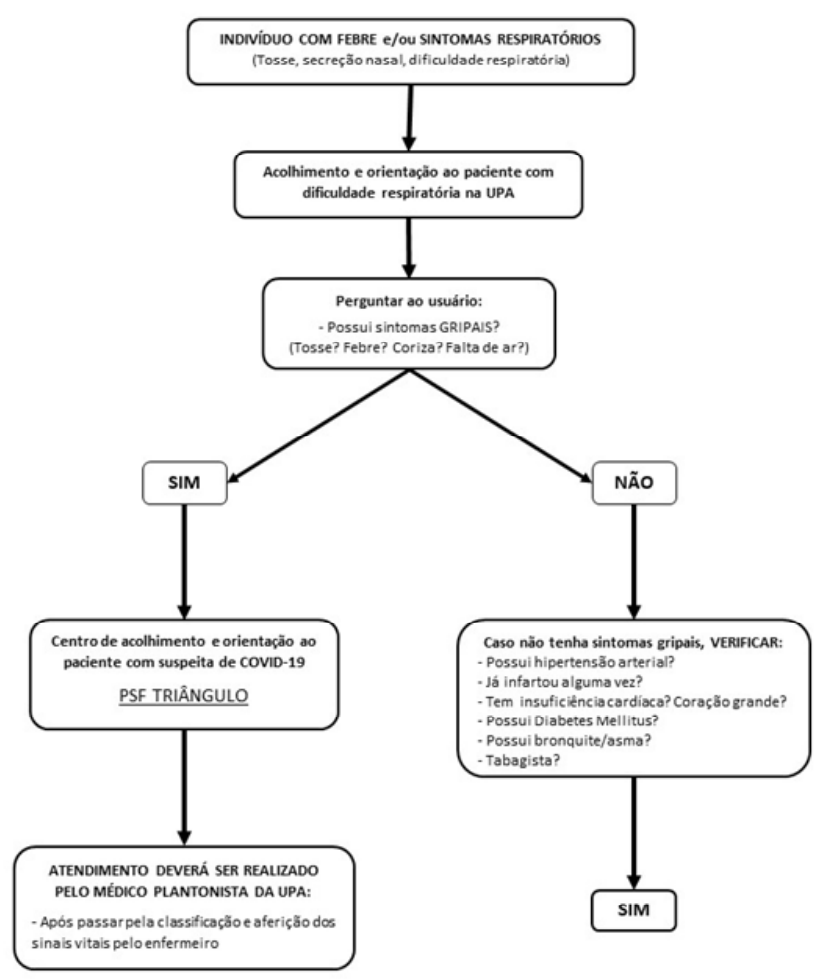

Figura 1. Criado para o Atendimento ao Paciente na rede estruturada para o enfrentamento à COVID-19 no Município de Três Rios, Rio de Janeiro, $\mathrm{RJ}^{11}$

Fonte: Autoria Própria

e superior a mundial, que é de $64 \%{ }^{12}$.

Em relação aos atendimentos, notou-se que há um pico de doentes a cada 10 -15 dias, compatível com o início do período inflamatório da COVID que é entre $8-12^{\circ}$ dia de sintomas, e prevalência de pacientes idosos.

A taxa de mortalidade no Município é de 2,0\%, alcançado índices melhores que a média Nacional de $3,1 \%$.

Baseada no compromisso e transparência das informações, a Prefeitura Municipal de Três Rios emite boletins diários em suas redes sociais com intuito de informar a população sobre a situação real do município. O serviço de Epidemiologia envia diariamente ao Governo do Estado as atualizações sobre casos novos, recuperados e óbitos, podendo ser consultado através do site.

\section{Discussão}

\section{Problemas}

Alguns problemas ou desafios foram encontrados 


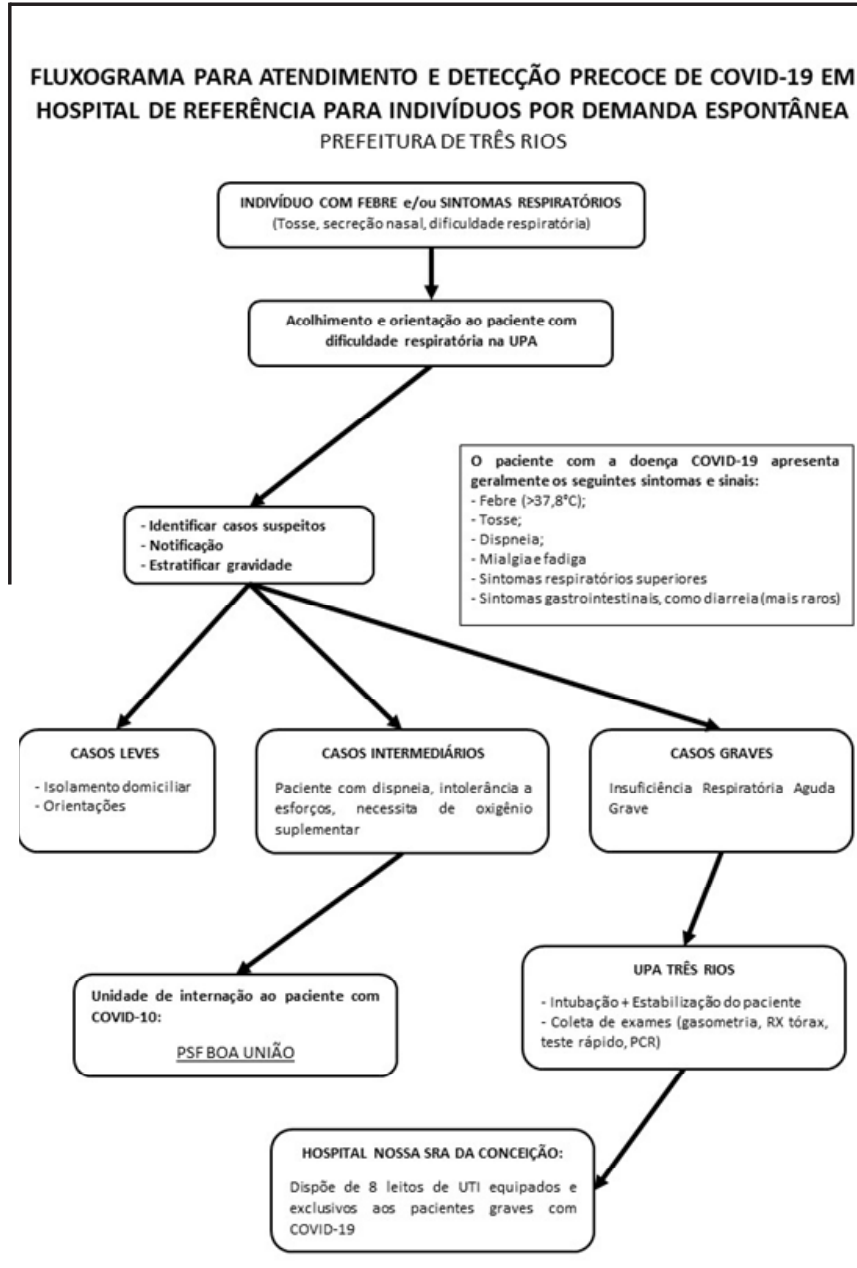

Figura 2. Criado para o Atendimento ao Paciente na rede estruturada para o enfrentamento à COVID-19 no Município de Três Rios, Rio de Janeiro, $\mathrm{RJ}^{11}$.

Fonte: Autoria Própria

ao longo da implementação dos serviços, uma vez que se trata de uma doença de comportamento e evolução incerta e pouco conhecida. Os sintomas mais comuns são referentes a quadro clínicogripal (tosse, espirros, coriza, febre, falta de ar), além de sintomas gastrointestinais que são menos comuns ${ }^{5,6}$.

Segundo a OMS, os pacientes mais afetados são os acima de 60 anos e portadores de comorbidades como hipertensão arterial sistêmica, diabetes mellitus e obesidade ${ }^{7-9}$. Porém, temos presenciado pacientes de meia idade com complicações graves e, até o momento duas crianças, uma de quatro e outra de seis anos que evoluíram clinicamente com síndrome da Angústia Respiratória Aguda Grave. Uma vez que as crianças não estão relacionadas com maior incidência de gravidade, não houve criação de Fluxos ou Protocolos voltada para elas.

Além de estarmos em Critério de Pandemia, devido a sazonalidade, observa-se um número de pacientes apresentando sintomas respiratórios como crise de asma, bronquite, pneumonia, o que dificulta ou deixa o profissional médico com receio e dúvidas sobre a conduta a ser tomada, uma vez que qualquer sintoma respiratório deve ser notificado como caso suspeito, seguindo recomendação da OMS.

O medo de contaminação por SARS-CoV-2 faz com que os profissionais tenham receio de examinar os pacientes de forma correta, propiciando ou aumentando a chance de diagnósticos errôneos e consequentemente desfechos desfavoráveis para os pacientes. Para isso foi promovido capacitações e disponibilizado EPIs para que o profissional possa entrar com contato com os pacientes internados sem que ponha sua integridade física em risco. Além de estar disponível uma equipe de psicólogos para prestar assistência necessária.

Outro ponto importante, é a falta de estruturação, criação de fluxograma e Protocolos de Enfrentamento por parte dos Municípios vizinhos. Três Rios recebe pacientes de Paraíba do Sul, Levy Gasparian, Areal, Sapucaia, Posse e de cidades pertencentes ao Estado de Minas Gerais, como Chiador e Santana do Deserto. Uma vez que a UPA acolhe esses pacientes, há dificuldade de transferir o paciente morador de outro estado ou o fluxo de saída é muito restrito, o que faz com os pacientes permaneçam longos períodos internados na UPA.

\section{Condução dos casos}

Com a evolução da Pandemia e o número crescente de pacientes sintomáticos, notou-se um hiato entre os pacientes contaminados com sintomas leves, representados pelos pacientes que não apresentam dispneia em suas atividades habituais, possuem uma pO2 $>80$, sTO2>94\% à gasometria, TC Tórax com comprometimento inferior a $25 \%$; que permanecerão em isolamento domiciliar e os pacientes críticos, definidos como os que apresentam dispneia ao repouso, $\mathrm{pO} 2<60$, sTO2 :94\%, TC Tórax com comprometimento $>25 \%$, serão internados em UTI.

$\mathrm{E}$ os pacientes com quadro intermediário? Onde seriam assistidos? Clinicamente, são pacientes portadores de dispneia com necessidade de suporte de oxigênio, uma pO2 entre $60-80$, sTO2<94\%, e TC Tórax com comprometimento até $25 \%$, porém ainda não são graves para serem admitidos em uma UTI. Para tanto, decidimos em conjunto com a Secretaria Municipal de Saúde, criar um Centro de Internação para Pacientes Intermediários. Foi utilizado um PSF de grande porte, próximo ao Hospital de Retaguarda - HCNSC, contendo 13 leitos, que serão assistidos a princípio por um médico, um enfermeiro e dois técnicos de enfermagem, no período de $24 \mathrm{~h} / \mathrm{dia}$. A unidade intermediária também receberá os pacientes que obtiverem alta da UTI-COVID que ainda necessitem de manter-se sob cuidados médicos até que possam obter alta para domicílio. 


\section{Conclusão}

Com tudo que tem ocorrido a nível mundial e nacional, conclui-se que a organização e implementação de protocolos é vital para o gerenciamento e desfecho favorável tanto para as equipes que estão na linha de frente dessa pandemia e principalmente para os pacientes. A prevenção com EPIs e manutenção do isolamento social tem sido fatores indispensáveis para o achatamento da curva de incidência de novos casos.

\section{Referências}

1. Guo Y-R, Cao Q-D, Hong Z-S, T, et al. The origin, transmission and clinical therapies on coronavirus disease 2019 (COVID-19) outbreak - an update on the status. Mil Med Res. 2020 Mar;7(1):11.

2. Ahn D-G, Shin H-J, Kim M-H, et al. Current Status of Epidemiology, Diagnosis, Therapeutics, and Vaccines for Novel Coronavirus Disease 2019 (COVID-19). J Microbiol Biotechnol [Internet]. 2020 Mar 28;30(3):31324. Available from: http://www.jmb.or.kr/journal/view.html?doi=10.4014/ jmb.2003.03011

3. Shereen MA, Khan S, Kazmi A, et al. COVID-19 infection: Emergence, transmission, and characteristics of human coronaviruses. J Adv Res [Internet]. $2020 \mathrm{Jul} ; 24: 91-8$. Available from: https://linkinghub.elsevier. com/retrieve/pii/S2090123220300540

4. Cai J, Sun W, Huang J, et al. Indirect Virus Transmission in Cluster of COVID-19 Cases, Wenzhou, China, 2020. Emerg Infect Dis [Internet]. 2020 Jun;26(6):1343-5. Available from: http://wwwnc.cdc.gov/eid/ article/26/6/20-0412 article.htm

5. Singhal T. A Review of Coronavirus Disease-2019 (COVID-19). Indian J Pediatr [Internet]. 2020 Apr 13;87(4):281-6. Available from: http:// link.springer.com/10.1007/s12098-020-03263-6

6. Coronavirus [Internet]. [cited 2021 Mar 24]. Available from: https:// www.who.int/health-topics/coronavirus\#tab=tab_3

7. Guan W, Ni Z, Hu Y, et al. Clinical Characteristics of Coronavirus Disease 2019 in China. N Engl J Med [Internet]. 2020 Apr 30;382(18):170820. Available from: http://www.nejm.org/doi/10.1056/NEJMoa2002032

8. Brooke J, Jackson D. Older people and COVID $\square$ 19: Isolation, risk and ageism. J Clin Nurs [Internet]. 2020 Jul 5;29(13-14):2044-6. Available from: https://onlinelibrary.wiley.com/doi/abs/10.1111/jocn.15274

9. Bialek S, Boundy E, Bowen V, et al. Severe Outcomes Among Patients with Coronavirus Disease 2019 (COVID-19) — United States, February 12-March 16, 2020. MMWR Morb Mortal Wkly Rep [Internet]. 2020 Mar 27;69(12):343-6. Available from: http://www.cdc.gov/mmwr/volumes/69/ $\mathrm{wr} / \mathrm{mm} 6912 \mathrm{e} 2 . \mathrm{htm}$ ?s_cid=mm6912e2_w

10. Ludvigsson JF. Systematic review of COVID-19 in children shows milder cases and a better prognosis than adults. Acta Paediatr [Internet]. 2020 Jun 14;109(6):1088-95. Available from: https://onlinelibrary.wiley. com/doi/10.1111/apa.15270

11. Magrani GC, Silva COP, Bandeira LLB, et al. Como me previnir do coronavírus? 1st ed. Interagir; 2020. 20 p.

12. Covid-19: Taxa de recuperados no Brasil é maior do que a mundial | Revista VEJA [Internet]. [cited 2020 Oct 3]. Available from: https://veja. abril.com.br/brasil/covid-19-taxa-de-recuperados-no-brasil-e-maior-do-quea-mundial/ 